\title{
Doing Online Relearning through Information Skills (DORIS): A Mutual Shaping Perspective for Information Literacy Research and Practice
}

\author{
Juan D. Machin-Mastromatteo and Sirje Virkus
}

\begin{abstract}
This article has been published as: Machin-Mastromatteo, J., Virkus, S.: Doing Online Relearning through Information Skills (DORIS): A Mutual Shaping Perspective for Information Literacy Research and Practice. In: Kurbanoglu, S. et al (eds.), Worldwide Commonalities and Challenges in Information Literacy Research and Practice, pp. 380--385. Springer, Heidelberg (2013)
\end{abstract}

The final publication is available at http://link.springer.com/chapter/10.1007/978-3-319-03919-0 50

\begin{abstract}
This paper is part of a doctoral research study about the integration of social media in a learning experience and the roles that information literacy, digital literacy, and new literacies may play in such integration. A pilot study was conducted and the final empirical study took place in April 2013. The methodological approach used is participatory action research (PAR) and following its logic as well as the results of the pilot study, the research and methodological framework labeled as 'Doing Online Relearning through Information Skills' (DORIS) was developed. This framework comprises a series of learning interventions, activities, and assignments. This paper provides early data analysis focusing on: a) its particular epistemological assumptions and supporting theories, b) the overall mutual shaping perspective assumed, and c) some of the possible contributions such study can offer to information literacy research and practice.
\end{abstract}

Keywords: social media, higher education, teaching, learning, participatory action research, information literacy.

\section{Introduction}

This paper is framed within a doctoral research study about the integration of social media in a learning experience and the roles that information literacy, digital literacy, and new literacies may play in such integration. A pilot study was conducted and the final empirical study took place in April 2013. The methodological approach used is participatory action research (PAR) and following this approach the research and methodological framework 'Doing Online Relearning through Information Skills' (DORIS) was developed [1]. This framework comprises a series of learning interventions, activities, and assignments, which are structured in the following five stages: 1) Introduction: participants start by completing the diagnostic questionnaire and then the researchers gives insights into DORIS' structure, its main concepts and methods, and mediates a common understanding of these conceptual tools that are going to be used; 2) Access: deals with user practices, information needs, location and selection, accessibility issues; 3) Use: its topics are, issues of social media, content curation, creation of social media sites, tool integration; 4) Evaluation: deals with the use of social media in organizations and the evaluation of social media sites; and 5) 
Wrap-up: includes final reflections together with the completion of questionnaires and interviews. This research is guided by the following main research question: What significant issues, challenges and opportunities emerge when social media are integrated into learning environments in higher education? Sub-questions to this study are: a) How do students' experience learning when they are engaged in a learning activity that integrates social media? b) In what ways are students' engagement dependent upon their literacies? c) In what ways do learning, literacies and social media mutually shape each other?

As stated before, the methodological approach taken in this research is Participatory Action Research (PAR) and the data collection methods are: a diagnostic questionnaire at the beginning of the study, and a second questionnaire and semi-structured interviews at the end. Other data collection instruments were taken into account for the data analysis by using content analysis. These instruments were a blog, which was used as a content and interaction hub, thus collecting all learning materials and the forums used, which contains messages from the participants that were analyzed as well. Also important for data analysis were the participants' assignments, which correspond to the stages 2, 3 and 4 of the framework mentioned above.

\section{Epistemological Assumptions, Main Concepts, and Theories}

The epistemological assumptions of this study are that knowledge is created through socialization [2], [3] and can be discovered [4], as people possess tacit knowledge [5]. Moreover, following PAR, teachers and practitioners are capable of generating personal theories by systematically studying their own practice [6]. The most important concepts used in this study are information literacy [7], [8], [9], digital literacy [10], [11], and new literacies [12], [13], [14]. The importance to make this distinction rather than adopting a multiliteracies approach lies in the fact that in an exploratory study data needs to be gathered on the challenges posed to the participants by different kinds of skills. For example, there could be participants who may be information literates, but have problems with the technologies used. In this case there is bound to be a difference in their level of engagement and success in participating in DORIS. The opposite case may happen; so called 'digital natives' can have problems seeking or evaluating information (information literacy skills), and consequently there will be a different kind of engagement and success for these participants. Furthermore, both kinds of participants might have challenges associated with new literacies. Throughout this research and thus this article, when the term literacies (in plural) is used, it intends to contain the three concepts provided above: information literacy, digital literacy, and new literacies. The main theories supporting this research are: constructivist, blended, and problem based learning; the three dimensions of learning, are cognitive, social, and emotional [15]; and as well the theory of affinity spaces [16] is addressed. These theories provide useful analytical lenses for analyzing and discussing the data gathered. 


\section{The Mutual Shaping of Learning, Literacies, and Social Media}

Within this research, learning, literacies, and social media are conceived as elements that mutually shape one another. This is called a mutual shaping perspective, which is opposed to the perspective of 'technological determinism'. It allows one to gain a better understanding about how technology might affect the practices of its users and at the same time gives a glimpse on how these practices may affect the way technology is used or implemented into teaching/learning contexts. Moreover, the use of social media can influence the way a learning experience is planned and the characteristics of a learning experience may change the way the educator plans the experience or uses this technology. When analyzing the data derived from this study, it is important to keep in mind that during the study the researcher familiarized the participants with the concepts of literacies and the three dimensions of learning and then mediated a common understanding of these concepts. This was done in order to give them a deeper understanding of the research objectives and main concepts so that they could reflect on their own learning experiences by using these conceptual tools [17].

In order to provide some early data analysis and remain within the space constraints of this article, the focus of the following analysis is narrowed to the participants' perspectives on the mutual shaping relationship of literacies, learning, and social media that happened during DORIS. The data included here is drawn from the final study, which was conducted with a group of 7 participating students of different disciplines and ages that were enrolled on a bachelor-level information literacy course. The number of data analysis instruments can be summarized as 7 diagnostic questionnaires, 21 assignments, around 95 forum messages, 7 follow up questionnaires, and 7 interviews, with an average time 40 minutes. Although it would seem that there were a small amount of participants, in this particular type of study, this amount of data collection instruments are added to the ones collected in the pilot study, which will feature prominently on the data analysis of the final work. This kind of research involves cyclical processes (e.g. pilot and final study) and the richness of the methods and the amount of data collection instruments that were used compensate for the small amount of participants. Even though this part of the data analysis is the first part of the results of the final study that have been made public, this is one of the most important parts of this research and the findings in relation to all the research questions will converge on this area.

All the participants agreed that learning, literacies, and social media were elements that mutually shaped one another during the study, thus partly confirming one of the main hypotheses of this research. When asked if these elements can mutually shape one another, one participant stated "yes, because today everything can be related, through social media you can make a topic of interest known. In fact, in this module we have demonstrated it, in this learning experience we have been demonstrating it." This remark, allows us to make two inferences. Firstly, participants confirm that they can take whatever they want to learn using any of the learning materials in the ways they wish, and bring any related topics to the forums, but not alter the main structure of the learning intervention (which was slightly changed after 
their early feedback, but that is a matter to discuss in the full thesis). This is something that has been a concern because the role of the participants is somewhat limited. However, the participants have made statements like the cited above: "we have been demonstrating it". If we go a little bit further with what content analysis allows us, regarding a matter of discourse, these types of claims indicate some kind of pertinence from the participants toward the study. Secondly, the part of the affirmation cited above that reads "today everything can be related, through social media you can make a topic of interest known", allows us to further support the claim made in the conclusion section below: DORIS can be integrated in other learning experiences dealing with other topics. It is possible to use this structure together with the mediation of social media for other topics. This will be further examined with the rest of the data gathered.

One participant could see that this relationship happens "if you can make someone literate, through social media, over different topics, even if teacher and student are separated physically." It can be inferred from the way this study was set up, that it allowed developing literacies regardless of the means, technology used, and the geographical separation between researcher and participants. Another participant claimed that "they [literacies, learning, social media] are all part of a process", pointing out the structured and systematic qualities of the learning experience, which allowed this mutual shaping relationship to emerge. Adding to this, the response of another participant argued, "they are mutually shaped because through one of them you can reach the other ones".

Another participant reflected on using their information literacy skills: the ethical use of information and the determination of information validity, stating, "young people have to learn that to be able to post everything is not an invitation to publish anything. I believe they have to learn what is publishable what is not, as well as knowing to differentiate what is valid information and what is garbage. Information competencies are for this."

\section{Conclusion}

There is still a long way to in order to complete this research. The data shown in this article is a small fraction of the richness and depth of the data collected. Moreover, as the answers of the students who participated in this study are important in empirically determining exactly how this mutual shaping relationship between literacies, learning and social media occurs, there are different 'living dialectics' [18] that will play a role in the final data analysis. Firstly, there is of course the dialectics between the empirically researched and the related literature; then the contraposition of participants' perspectives from both the students who participated in the pilot as well as in the final study, because one of the methodological precepts of PAR that has been adopted is that it is "a cyclical process of exploration, knowledge construction, and action at different moments throughout the research process"[19], which could potentially be repeated ad infinitum. Finally, there is the tension between the pilot and the final studies from the perspective of the research, which is a part of the analysis as 
well, in order to be able to achieve a reflection on the researcher's own practice, and thus generating a personal and systematic theory [6].

Because this is ongoing PhD research, the remaining conclusion of this article is some of the possible contributions that such study can offer to information literacy research and practice. Thus, different researchers, librarians, teachers, and related professionals can use its elements to enrich their social investigations, information literacy programs, and their pedagogies. Some elements from this study worth considering by practitioners are the three dimensions of learning and the concept of affinity spaces. Moreover, other elements of interest might be the epistemological assumptions, PAR methodology and DORIS as a research framework that provides a structure and an example of instructional design based on learning objectives, theoretical presentations, examples, learning activities, and supporting reading materials (not reproduced in this article for space constraints). DORIS allows differentiating literacies (information literacy, digital literacy, and new literacies) skills that the participants of this study can be using or enhancing at each of the research stages. During research, the roles that literacies play in this type of learning experience are expected to emerge. DORIS is proposed as an effective way to organize learning interventions through an information skills structure. This model has been grounded on research and inquiry learning pedagogies as well as in PAR and constructivist learning, which can be a blended one. Practitioners may adapt this research framework to develop learning interventions with the objective of learning and researching with and about social media or other technology mediated learning environments. It can be adapted to facilitate information literacy programs and teach some subjects by going through the aspects of access, use and evaluation of the information related to the topic. It can be a useful framework for scaffolding learning by going through the different information skills that are needed to research and manage the information, resources or devices related to different disciplines.

\section{References}

1. Machin-Mastromatteo, J. D.: Participatory Action Research in the Age of Social Media: Literacies, Affinity Spaces and Learning. New Library World, 113(11), 571--585 (2012)

2. Vygotsky, L. S.: Mind in Society: The Development of Higher Mental Processes. Harvard University Press, Cambridge (1978)

3. Nonaka, I., Takeuchi, H.: The Knowledge Creating Company: How Japanese Companies Create the Dynamics of Innovation. Oxford University Press, New York (1995)

4. Whitehead, J., McNiff, J.: Action Research: Living Theory. Sage, London (2006)

5. Polanyi, M.: Personal Knowledge. Routledge and Kegan Paul, London (1958)

6. Whitehead, J.: Creating a Living Educational Theory from Questions of the Kind 'How do I Improve my Practice?' Cambridge Journal of Education, 19 (1), 137--53 (1989)

7. Zurkowski, P. G.: The Information Service Environment Relationships and Priorities. National Commission of Libraries and Information Science [USA], Washington (1974)

8. Tuominen, K., Savolainen, R., Talja, S.: Information Literacy as a Sociotechnical Practice. Library Quarterly, 75(3), 329--345 (2005)

9. Lau, J.: Guidelines on Information Literacy for Lifelong Learning. IFLA, Veracruz (2006)

10. Shapiro, J.J., Hughes, S.K.: Information Technology as a Liberal Art: Enlightenment Proposals for a New Curriculum. Educom Review, 31(2), 31--35 (1996) 
11. Lankshear, C., Knobel, M.: Digital Literacy and Digital Literacies: Policy, Pedagogy and Research Considerations for Education. Nordic Journal of Digital Literacy, 1(1), 12--24 (2006)

12. Gee, J. P.: New Times and New Literacies: Themes for a Changing World. In: 8th International Literacy \& Education Research Network Conference on Learning, pp. 3--20. Spetses, Greece (2001)

13. Lankshear, C., Knobel, M.: Researching New Literacies: Web 2.0 Practices and Insider Perspectives. ELearning, 4(3), 224--240 (2007)

14. Lankshear, C., Knobel, M.: New Literacies: Everyday Practices and Social Learning. Open University Press/McGraw-Hill, Maidenhead \& New York (2011)

15. Illeris, K.: Towards a Contemporary and Comprehensive Theory of Learning. International Journal of Lifelong Education, 22(4), 396--406 (2003)

16. Gee, J. P.: Good Video Games and Good Learning: Collected Essays on Video Games, Learning and Literacy. Peter Lang, New York (2007)

17. Wertsch, J. V.: Mind as action. Oxford University Press, Oxford (1998)

18. McTaggart, R.: Participatory Action Research: International Contexts and Consequences. State University of New York Press, Albany (1997)

19. Mclntyre, A.: Participatory Action Research. Sage, Thousand Oaks (2008) 